\title{
Dynamics and city-region regeneration economies: shaping the directions of a new research agenda
}

\author{
Lauren Andres and John R. Bryson
}

\section{Introduction}

This book brings together a collection of chapters that identify or define the ongoing research agenda on city-regions across the world. The focus is on city-regions located in a context of 'regeneration economies' or in other words, areas that are experiencing an ongoing process of recovery, adaptation or in-depth transformation. This process of transformation is occurring in all city-regions, but with different drivers, both exogenous and endogenous, and with variations in intensity and impacts. There is no such thing as a representative or standard city-region. Every city-region is a distinct, even unique, bundle of assets or resources including subjective ones such as reputation, heritage and stories that are told of that place. In addition, every city-region has different degrees of local, national and international connectivity. At the centre of the analysis of city-regions is heterogeneity and a complex interplay between place, space and a concatenation of spatial and sometimes aspatial processes (Massey, 1984). It is important that those aspatial processes are not conflated with processes that have a distinctive and often iterative relationship between place and space. In addition, endogenous and exogenous place-based processes are often the outcome of irrational or semi-rational decisions made by local decision makers, stakeholders, communities and households based on information asymmetry and bounded rationality. This complex interaction between place and decision-making processes leads to heterogeneity and perverse consequences or impacts that may be perhaps impossible to explain. Thus, regeneration economies have characteristics and processes that are often idiosyncratic and serendipitous.

The heterogeneity of city-regions is further complicated by size. Research on cityregions has, we suggest, been patchy and overwhelmingly dominated by studies of special places, mainly in the so-called Global North rather than the Global South. These special places tend to be, on the one hand, city-regions that have experienced processes of restructuring in response to economic decline including deindustrialization. These are often problem places with high unemployment rates. On the other hand, is a focus on global city-regions (Scott, 2002); special places considered to be the command and control centres of the global economy or global technological 
or digital creative hubs (Keeble, 1989; Massey et al., 1992; Garnsey and CannonBrookes, 1993; Garnsey and Heffernan, 2005). It is perhaps understandable that studies of selected city-regions have been dominated by attempts to produce theory or the identification of generalizable city-region processes. The emphasis on special places is to ignore or neglect more ordinary city-regions. This is surprising as the majority of people live in more ordinary city-regions (Parkinson et al., 2015). This reflects Robinson's call for the development of a research agenda on 'ordinary cities' (Robinson, 2005) or those smaller cities that have been overlooked by urban theorists (Bell and Jayne, 2009; Mayer and Knox, 2010; Mayer et al., 2016). In the US, for example, nearly 45 million people live in cities of over $250,000,40$ million live in places of between 50,000 and 250,000, and 40 million in cities of between 10,000 and 50,000 (Clancey, 2004). This highlights the importance of smaller towns and cities and also the imbalance of urban research that tends to focus on global cities and cities with populations of over 1 million.

All city-regions are connected to the global economy, but in very different ways. Some play an important role as locations for people, firms and institutions which themselves directly contribute in shaping the ongoing evolution of globalization, while other city-regions are recipients of processes and decisions that are determined elsewhere. These could be argued to be more peripheral places. Nevertheless, it is important that a more inclusive research agenda on city-regions develops that focuses on small, middling and large city-regions (Parkinson et al., 2015). Such research should explore local practices, processes, routines, everyday living, lifestyles, differential connectivity as well as capitalist and non-capitalist forms of economic activity. In this context, it is important not to ignore Gibson-Graham's analysis of the end of capitalism as we know it when they noted that:

[O]ne must represent economic practice as comprising a rich diversity of capitalist and non-capitalist activities and argue that the non-capitalist ones had been relatively invisible' because the concepts and discourses that could have made them "visible" have been marginalized and suppressed. (Gibson-Graham, 1996: xi)

This point highlights the importance of understanding heterogeneity, diversity and the complexity of economic practices within city-regions (Bryson et al., 2018).

City-regions are part of the research agenda of many different and often unrelated academic disciplines. The physical and engineering sciences are concerned with the ongoing engineering of the infrastructures which support city living combined with a concern with the transformation of nature and its management (Hunt et al., 2012; Rogers et al., 2012; Hale et al., 2015; Leach et al., 2017). The medical sciences are concerned with healthy cities and more precisely healthy citizens. There is an interesting ongoing research relationship occurring between medicine and the physical sciences reflecting a concern with air pollution and environmental pollution more widely and the impacts on health (Harrison and Beddows, 2017; Samoli et al., 2016; Crilley et al., 2015; Exley et al., 2014). The social sciences have many ways of defining, seeing or reading city-regions. These include spatial 
planning, governance and regulation, cultural and environmental accounts, economic geography and regional science and analysis in which the focus is on the region as a site for foreign direct investment (FDI) and international business or entrepreneurship.

One definition of a city-region is as a complex system of systems. These systems are both the outcome of engineering involving concrete, cement, steel, glass, pipes and cables and socio-economic systems based on money, technologies, people, cultures, lifestyles, governance and history. One of the starting points for this analysis was a book published in 1913 on the cutlery industry. This is perhaps a strange starting point, but in this account, Lloyd argued that:

The study of an individual trade, considered in isolation from other trades, can only yield a result as partial in its significance as is a single thread abstracted from a woven tapestry; to obtain a full understanding, the selected trade must be viewed in its setting in the entire fabric of industrial life. (Lloyd, 1913: 1)

This metaphor of thread and tapestry is to argue that the complexity of city-region economies requires new ways of imagining, describing, and analysing. This is to argue that like an industry a city-region must be considered and conceptualized holistically, which is a major academic and policy challenge.

There are many ways of researching city-regions. In the social sciences, there are grounded approaches that begin with a focus on regions or agglomerations and eventually situate these within the context of national and international flows. This is a perspective that is based on understanding city-region relationships and processes and their local, national and international relationships. An alternative perspective is not grounded within regional economies, but rather highlights the ways in which international processes and decisions impact on and become grounded in city-regions. These accounts begin with assumptions about the international or the global and then explore how these relate, in some ways, to city-regions. The latter account reflects approaches developed in international business and on global value chains (GVC) (Gereffi et al., 2005; Ponte and Sturgeon, 2014) or global production networks (GPN) (Coe and Yeung, 2015). There are many alternatives including research that focuses on individuals, households or firms, urban governance and processes of financialization (Torrance, 2009; Bryson et al., 2017b). Beyond the social sciences, the engineering disciplines provide an alternative perspective highlighting different layers within city-regions including sub-surface processes - pipes, cables and tunnels - and surface processes - roads, pavements, railways. As a consequence, there are many different ways of modelling city-regions and all these numeric or econometric models are disconnected or isolated. In fact, there is no attempt to develop an integrated model. There are health, energy, transport, engineering, planning and economy models and each type adopts different modelling approaches. None model the complexity of city-regions as they all adopt a partial view by attempting to model one element or thread in the complex tapestry that is a city-region. 
To complicate matters, city-regions are complex, dynamic and evolving systems of systems. They are in a continual state of flux and transformation. Any definition of a city-region must include a dimension of change and this implies that all city-regions are in a continual state of becoming with perhaps no clearly defined direction of travel. Evolutionary economic geography highlights the importance of the impacts of an accumulation of incremental decision-making producing path dependency, path creation or lock-in (Boschma and Martin, 2010; Martin, 2010, 2012). This path dependency is grounded in accumulations of incremental decision-making that can be traced back centuries. Hence, there is a major research and policy challenge. This is the development of more integrated or less siloed approaches to understanding city-regions or regeneration economies. There are two types of silos to consider. On the one side, there are policy siloes in which the organization or governance of cityregions is sub-divided between distinct institutions and policy-makers. It is often the case that housing policy is separated from economic and skills policies. These policy silos lead to perverse consequences including inefficiency and a failure to break from path dependencies that produce negative consequences for people living in a cityregion. On the other side, there are academic disciplinary silos in which disciplinary boundaries and the institutional and governance structures, including disciplinaryfocused research assessment exercises and research funding models that support research and scholarship, discourage interdisciplinary, multi-disciplinary or transdisciplinary research. This is more than unfortunate, as these academic silos are holding back research that could potentially transform city-regions for the better.

This collection brings together a set of what are arguably siloed approaches to understanding regeneration economies. Each chapter focuses on one aspect of a regional economy, but the challenge is to begin the process of bringing these approaches and debates together. Cutting-edge research that must be undertaken can be identified within each of these areas, but arguably the critical challenge is in developing a multi-dimensional and multi-disciplinary approach to understanding city-regions. This requires both academics and policy-makers to set aside boundaries and to develop more integrated and systematic approaches to the problems being experienced by city-regions. This is a major challenge because the task is both multi-disciplinary and multi-scalar. The scales include micro or firm-level analysis, meso or regional-level analysis and macro or international or global. There are, however, many other scales including that which can be termed the sub-micro or decisions made by individuals and households. These could perhaps represent a nano-scale of decision-making. City-regions must be increasingly conceptualized as the outcome of billions of decisions that are layered on top of one another in complex arrays. It is the accumulations of these often isolated decisions that produce city-regions. Some of these decisions are transformational including the development of new buildings and infrastructure, but the majority might be considered to be trivial and many have become routine, automated or taken-for-granted decisions that are invisible to both the decision-taker and the social scientist.

All this suggests that the object of study, that is a city-region, is extremely complex, consisting of interactions between people, place, space and hard and soft 
infrastructures. The processes, structures, people, investments and intra- and interregional relationships that comprise a city-region are diverse, evolving and cumulative. Social, economic, technological, behavioural, cultural and political changes constantly alter the internal and external dynamics of city-regions. Along with this are alterations in systems of governance and also socio-economic and technical regulations or conventions that act as barriers and enablers to innovation. Some of these alterations are minor and some represent periods of major disruption or revolution as processes, systems, activities or practices are altered or destroyed. Revolution is an ambiguous and controversial word; a 'revolution' should not be considered as the antithesis of a more evolutionary approach (Boschma and Martin, 2010), but rather best describes a transformation occurring in a relatively short time. Revolutions may be experienced and identified as a major period of rapid transformation or may be identified towards the end of a period of transformation that might be the consequence of many incremental alterations that combined are transformational. City-regions defined as regeneration economies highlights the importance of dynamics and continual evolution.

\section{Deconstructing city-regions through the lens of regeneration economies}

City-regions consist of many different strands that are too intricately woven together to be completely unravelled. Academic research examines particular processes, activities, industries, structures, investments and behaviours in detail. It is important not to lose sight of the layering of many interdependencies within and between city-region socio-economies or to imply that in isolating processes, structures or activities that the research or policy process makes them appear to be more significant than any other. Central to city-regions are mutual interdependencies. These may be very explicit and defined geographically as processes of co-location, co-dependency, agglomeration or clustering, but they also include mutual dependencies that link city-region with city-region in an ever-evolving set of interactions based around movements of ideas, people - consumers and producers - raw materials, components and products.

There are many different existing definitions of cities and regions which need to be explored as part of an exercise in defining the object of study. To Walter Isard, the founder of the discipline of Regional Science, "the region has its own 'essence' which can be grasped in full only by tools, hypotheses, models and data processing techniques specifically designed for regional analysis" (Isard, 1956: 17). The word 'essence' stands out from this account of tools, hypotheses and models and perhaps reflects some of the fundamentals of city-regions. To Woodward, the use of the term essence in this statement has a 'metaphysical ring' but he then argues that he considers 'Isard's 'essence' to mean that the region is fundamental and necessary, and importantly, something that we can detect and measure through empirical research" (Woodward, 2017: 121). This is an economist's view of essence, but this essence is more than just about measurement. There are many aspects of 
the 'essence' of a region that cannot be measured and perhaps are better imagined or more precisely experienced.

An alternative perspective, or the application of a metaphysical term, is found in discussions of cities and, in particular, Massey's application of the word 'intensity' to cities. Thus, in this context, the intensity of a city is partly derived from "the city as speeded-up interconnections set within an ever spatially-spreading web of external connections" (Massey, 1999: 159) and central to this intensity is size, density, heterogeneity and the transformation of nature. Essence and intensity are interesting concepts and perhaps better than focusing on density. There are still many alternative definitions. Thus, to Scott city-regions are "dense nodes of human labor and communal life scattered across the world" and these "nodes constitute distinctive subnational (i.e. regional) social formations whose local character and dynamics are undergoing major transformations due to the impacts of globalization" (Scott, 2002: 1). To Scott a new regionalism has emerged in which some 'global city-regions' have emerged which are regional social formations that have developed a distinctive identity and economic and political force on the world stage. Thus, some regions are more important than others in terms of the ways in which they are incorporated in to the ongoing developing global economy. In this account, these are 'global city-regions' and perhaps 'national or local city-regions', but this is to ignore other places that could be described as less special or more ordinary city-regions.

A key issue to consider is then the definition of a regeneration economy. A regeneration economy may be a city-region or any place that has or is experiencing considerable economic turbulence. This may be the outcome of processes of deindustrialization (Bluestone and Harrison, 1982), reindustrialization, the reshoring of manufacturing (Vanchan et al., 2018) or the application of new technologies to production processes. The emphasis is on the economic aspect of place, but this should not be isolated from other processes and factors. There are interesting causal relationships between place-based non-economic factors and economic activity. Migration may be the result of a non-economic driver but with economic outcomes. In the 19th century, Birmingham, UK, became the workshop of the world or the city of a thousand trades. Birmingham's transformation can be traced back to the second half of the 17th century when the city's "population was greatly strengthened by the coming to their town of numerous dissenters [nonconformists], who brought new ideas and perhaps new trades" (Hamilton, 1926: 332). These religious migrants were "men and women of strong character, since they had stood out and suffered persecution for conscience sake, and their qualities of independence and reliance, frugality and temperance could be turned to good account in the ordinary business of life" (Hamilton, 1926: 125-126). The contribution migrations make to regional economic transformation should not be understated. Migrants bring new ideas, practices and connections to other places. In a detailed study of ethnic minorities and migration to the city of Bristol from 1000 to 2001, Dresser and Fleming noted that "the reception of a particular ethnic group largely depends on what skills and capital it brings to the receiving economy and how intolerance 
can increase against minorities who are perceived to have outlived their economic usefulness" (Dresser and Fleming, 2009: 219). Migrants have been for over 1000 years a source of tension within city-region economies. In Bristol debates regarding migrants stealing jobs from local people can be traced back to the 15th century (Dresser and Fleming, 2009: 219). Diaspora networks play an important role in linking people and places together through family and friendship relationships. These relationships take many forms including flows of money and ideas which may lead to migrants establishing new businesses in a host economy (Harris et al., 2012, 2014, 2016).

Regeneration economies have a number of identifiable characteristics. Economic turbulence may have destroyed or led to radical restructuring of existing industries (Bryson and Ronayne, 2014). There may be a qualification or skills mismatch between existing, declining or restructuring economic activity and the emergence of new industries. A regeneration economy might be the outcome of an ongoing spiral of economic decline as firms experience new forms of competition or the emergence of alternative business models destroys existing ones. One driver behind regeneration economies is the failure of local firms to continue to innovate and to adapt to alterations in consumer demand and in competition. Some characteristics of a regeneration economy are places with high unemployment, social exclusion and in some instances urban decline including shrinkage. These more extreme forms of regeneration economy are associated with a decline in the quality of the urban environment and a challenging real estate market in which a collapse in demand leads to empty and derelict properties. Such places will have infrastructural problems reflecting under-investment in schools, hospitals and transportation. It is important to recognize that there are feedback loops between some of these processes that have the potential to intensify a spiral of decline. One of these feedback loops is the establishment of a place-based identity, a reputation or even place-based brand that might discourage external investment and in-flows of migrants.

A city-region may be defined as a regeneration economy - a region undergoing considerable disruptive change involving failing firms and high unemployment. Alternately a regeneration economy may be undergoing processes of incremental change in which an economy is being transformed, but without high unemployment rates. It is important to consider scale in any discussion of city-regions. A city-region consists of many different types of local economy and labour market. This is an important point. Some places within a city-region may be experiencing radical regeneration or transformation and other parts of the city-region undergoing incremental adaption. A city-region is a mosaic of different types of place - large cities, small towns and villages - with each place having a different relationship with the overall city-region and also different relationships with other cityregions. Defining city-regions as regeneration economies highlights the importance of developing a more integrated understanding of the different layers and strands of a city-region while positioning change and transformation at the centre of the analysis. This is to argue for the development of a research agenda on city-regions that highlights dynamics or processes driving change and transformation. 


\section{Dynamics, change, transformation and timeless processes}

It is important to consider processes and drivers of change and transformation within and between city-regions. This enables city-region regeneration economies to be conceptualized as a trajectorial process. It is possible to identify a set of what can be termed 'timeless' processes that emerged with the development of capitalism and continue to transform space and place. These timeless processes produce different outcomes depending on context. One of the challenges facing research in to city-regions is to identify and characterize these timeless processes and to explore their impacts at different times and in different places.

The primary timeless process is perhaps the 'division of labour' (Smith, [1776] 1977) and the 'spatial division of labour' (Massey, 1984). This process refers to the disaggregation of complex tasks into several simpler tasks that can be undertaken by different individuals or groups of individuals. This division of tasks can occur on the same site or at the same location, or tasks can be transferred to other places and a spatial division of labour (Massey, 1984) emerges that is the foundation for global value chains or global production networks. There are three important points to make about the division of labour. First, a division of labour always precedes mechanization; tasks are disaggregated facilitating the identification of which tasks can be mechanized or replaced with artificial intelligence and robotics and which are more effectively undertaken by people (Bryson et al., 2017a; Bryson, 2018). Second, the division of labour is the primary driver behind global value chains. At a city-region scale, tasks may be allocated to one place given the existence of concentrations of specialist labour or other forms of place-based processes or incentives that provides a specific city-region with a competitive advantage in the performance of a task. Third, the division of labour is ongoing. Day-by-day decisions are made to further sub-divide tasks and to replace people with machines or robots and also to alter the geographic distribution of tasks. In this process, jobs are restructured or reshaped, some jobs are destroyed and new jobs emerge (Bryson, 2018).

The division of labour is too often identified with Adam Smith ([1776] 1977) and his analysis of the ongoing transformation of the organization of work in a pin factory. For example, David Harvey notes that the division of labour developed "from simple beginnings in Adam Smith's example of the pin factory" and this has "over time grown to encompass much of what is now covered in management and organisation theory" (Harvey, 2014: 98). This attribution of Smith to the identification of this concept is incorrect. In The Wealth of Nations (1776), Smith does identify, define and characterize the division of labour, but he was not the first scholar to identify this process. The concept can be traced back to Plato's Republic, a Socratic dialogue written around 380 BC. In this dialogue Plato discusses with Adeimantus the benefits associated with a division of labour and specialization. In this account the origins of the state are grounded in inequality between people and this inequality is embodied in the division of labour. This division of labour results in the development of specialization within labour markets. 
There is a substantial literature on the division of labour, but the first 'modern' analyst of this process was not Adam Smith but William Petty in his book on political arithmetic published in 1678 . In this analysis Petty explored watch making noting that:

In the making of a Watch, if one man [sic] shall make the Wheels, another the Spring, another shall engrave the Dial-plate, and another shall make the Cases, then the Watch will be better and cheaper, then if the whole work be put upon one man [sic]. (Petty, [1678] 2004: 16)

The division of labour is a timeless process that continues to shape both the technical and social division of labour. The former refers to tasks that anyone would be able to undertake in principle, while the latter to specialist tasks that require specialist training or social or physical attributes. To David Harvey, the "division of labour should, by rights, be positioned as one of the foundational features of what capital is all about" (Harvey, 2014: 112). It is also a process that advantages groups of people as the division of labour is associated with differential pay but also produces inequalities and the emergence of temporary work and other forms of precarious employment. The division of labour also involves a spatial division of labour with places, regions or even countries specializing in the delivery of specific tasks and functions. The spatial division of labour (Massey, 1984) is also a process that marginalizes places while, at the same, ensuring that other places function as the control and co-ordination centres of the global economy.

The division of labour underpins or is the primary process behind the emergence of global value chains (GVC) (Gereffi et al., 2005) or global production networks (GPN) (Yeung and Coe, 2015: Coe and Yeung, 2015). In fact, it is possible to argue that all GVC/GPN organizational forms are an application of the division of labour or more correctly an exercise in the identification, co-ordination and control of a spatial division of labour (Massey, 1984). Central to the GVC/GPN debate are the application of two metaphors - chains and networks. Both metaphors have been established in the literature and both have advantages and disadvantages. There are perhaps two fundamental difficulties. First, is that both metaphors suggest linear relationships in the operation of a spatial division of labour. Some production processes are linear, but many include complex feedback loops and organizational or project management strategies intended to provide a GVC/GPN with resilience. Resilience includes dual or triple supply of parts, raw materials and components to try to ensure continuity of supply (Nordigarden et al., 2014). The GVC/GPN research needs to focus more on understanding the complexity and heterogeneity of production processes (Sunley, 2008). This includes mixed strategies between supply chain governance forms that include both 'make' and 'buy' approaches. An in-house production dominant strategy may be complemented by outsourcing to optimize capacity utilization while the presence of some in-house production maintains complementary competencies and avoids path dependency in outsourcing-dominant strategies. 
Second, the use of the terms chain and network hides the labour within these international and sometimes global production networks/chains. The debate shifts away from one about labour and people to one about the strategic organization of capitalist relationships. This is more of a debate about management, strategy and operations than about the interrelationships between people, place and production processes. This raises an interesting question of why the debate on the organization of international or global production chains or networks does not return to an elaboration of the concept of a 'spatial division of labour'.

There is an earlier concept that emerged in economic geography in the $1960 \mathrm{~s}$ (Keeble, 1969) that can be traced back to much earlier debates (Florence, 1953: 85). This concept is one of 'linkage' and 'linked' processes, products and services. The early research on 'linkage' applied this concept to localization or processes of agglomeration, clusters, clustering or new industrial districts (Florence, 1953: 85). Thus, according to Florence "what has not been valued at its true importance in a large localization of an industry is the possibilities of division of labour between plants in 'linked' processes, products and service industries" (Florence, 1953: 85) or, in other words, linked enterprise structures that operate at different spatial scales from the very local to the global. This analysis highlights processes of localization rather than the emergence of processes that are organized and co-ordinated internationally or globally. But, it is worth appreciating the emphasis placed by Florence on the relationship between the organization of a division of labour and linkage and, in particular, linkages between processes, products and services.

The application, even overuse, of the terms 'network' and 'networking' to the analysis of the geographic organization of economic activities needs to be challenged. These terms have become another form of 'stylised fact' (Clark, 1998) or 'mesmerising mantra' (Taylor, 2010). These concepts are imposed upon economic relationships through theoretically-loaded social science and consultancy practices. There are many problems with considering economic relationships as network relationships. First, individuals do not experience networks, but rather networks are something that are observed from above with social scientists looking down from on high at economic and social relationships. The second point builds upon the first. Individuals engage with other individuals in dyadic encounters rather than as part of a network. A dyad is a group of two individuals interacting with one another in some way. A dyad is the smallest possible group. A dyad includes all types of one-to-one encounters - family, friendships, employment, business transactions - and like all relationships experiences different forms of asymmetry. This includes asymmetric information, but also visible and less visible forms of power imbalance. The term linkage reflects accumulations of dyads or dyadic encounters. The strength of these linkages can be measured in many ways including the frequency of the encounters, their extent but also their intensity. Dyads may be unstable relationships as one party to a dyad may engage in activities that alter the balance of power or enhance some other form of asymmetry. This may include the trust-based element of a dyad failing. Linked enterprise structures are based on dyadic communications or encounters in which some form of interrelationship, or 
transactional interaction, is established between two people that has some form of lasting or even measurable impact.

There is an important point to consider here. The literature on city-regions focuses on understanding processes and practices which are localized in some manner. The emphasis begins with the city-region and works outwards from regional to international or global (Scott, 2002). An alternative perspective or starting point for an analysis is to begin with the global and explore how the global is grounded, or strategically coupled, in specific places (Coe et al., 2004). These are very different ways of conceptualizing economic activity. One prioritizes local or regional process while the other prioritizes global processes. The challenge is how to reconcile these two apparently contrasting approaches. One could argue that these are two opposing sides of a continuum. Alternatively, the production of different products and services, or different ways of organizing production, will adopt different approaches: local or regional to international; international to regional or local. Thus, some production processes are heavily localized or organized nationally and others adopt a complex and dispersed spatial division of labour or global production chain/network or linked enterprise structure approach. It is worth noting that even within the same industry different firms will organize their production processes in different ways - from localized to dispersed. The geographic organization of production is extremely heterogenous reflecting incremental decision-making processes that are never completely rational. There is no single one-size-fits-all theory. Thus, some products and services are delivered or organized via global production networks, but many products and services are created using very different ways of organizing people, resources, place and space.

A very different timeless process revolves around the actions of nation states as they try to regulate, control, co-ordinate and encourage economic activity. These activities can facilitate the development of economic activity in city-regions but can also destroy industries. The West Midlands, UK, benefited from a series of Acts of Parliament that prohibited imports from France. In 1662, an Act was passed prohibiting the import of foreign buttons. This Act was intended to encourage needleworkers but also indirectly stimulated the manufacture of metal buttons in Birmingham. In 1688, all trade and commerce was prohibited with France resulting in the development of Birmingham's gun industry but also the manufacture of luxury and artistic goods (Hamilton, 1926: 127). In Coventry, the town's ribbon-weaving industry was destroyed almost overnight. In January 1860, the Cobden Treaty was signed. This was an agreement between Britain and France that removed many tariffs imposed on goods imported from France, including ribbons. One consequence was that the Coventry ribbon industry collapsed, and a national appeal was launched to support the town's weavers which raised $£ 40,000$. By 1862 , it has been estimated that up to 4,000 weavers and their dependants had left the town and migrated further north or to the US. Between the 1861 and 1871 censuses the population of Coventry declined by 3000 (Walters, 2013: 184-185). 
The relationship between public policy and economic activity thus needs to be explored in the context of city-regions. There are perhaps four core relationships to consider. The first includes the regulation of international trade with a focus on the negotiation of trade treaties. Such treaties can destroy existing economic activity or encourage FDI and the growth of local producers. Second, there are spatial planning interventions including the release of land for development and residential use, but also interventions intended to encourage the relocation of economic activity. Third, connectivity plays an important role in city-region resilience, sustainability and economic performance. Thus, public sector interventions, in the provision of all types of infrastructure, play a critical role in facilitating city-region activity. This includes international connectivity through investments in airports and ports but also national and local infrastructure. Some of this infrastructure will be funded and financed by the private sector, but this type of infrastructure is heavily regulated and controlled by government. Fourth, soft infrastructure plays a critical and often neglected role in enhancing the quality of everyday living in city-regions and has a direct impact on economic activity. This includes investment in education, health and cultural infrastructure and the residential environment. The latter is partly related to green infrastructure. These more softer infrastructures play a critical role in enhancing the attractiveness of places contributing to the retention and attraction of skilled labour.

The concept of timeless theory needs to be considered and a debate needs to develop regarding the primary timeless theories that enhance understanding of city-region regeneration economies. There would appear to be very few timeless theories or even laws. In 1970, Tobler famously identified what he termed "the first law of geography; everything is related to everything else, but near things are more related than distant things" (Tobler, 1970: 236). This 'law' draws attention to the importance of the localization of relationships of all types - social, economic, financial and service. Developments in information and communications technology, including online platforms, continue to transform the relationship between geography and economic activity. The application of digital platforms, including the Cloud, to the creation and delivery of products and services is reconfiguring globalization and leading to the development of a third wave of globalization (Kenney and Zysman, 2016) that is altering the relationship between the ways in which individuals work, socialize, compete and create value. It is transforming production processes and challenging existing business models and global production networks (Reuver et al., 2017). It is also altering the application of Tobler's first law of geography - the benefits of proximity are increasingly challenged by developments in digital platforms.

There is finally another debate to have regarding timeless theory and this is to focus on the criteria for evaluating theory. A theory is "a statement of relations among concepts within a set of boundary assumptions and constraints" and the function of a theory is to "organise (parsimoniously) and to communicate (clearly)" (Bacharach, 1989: 496). Many city-region theories are in fact not theories, but collections of constructs and variables. They are best described or classified as 
frameworks. Some of these frameworks confuse rather than elucidate and hence need to be used with care.

\section{Regeneration economies, irrationality, serendipity and idiosyncratic behaviour}

There is a danger that city-regions are seen to be the outcome of processes of rational decision-making. This is not the case. Decision-making is always based on partial information and information asymmetries. Many decisions are idiosyncratic, and some are serendipitous. All decisions involve trade-offs and often they are the outcome of negotiation processes that are informed or distorted by political and cultural factors. The irrationality of many decisions must be acknowledged as a core challenge facing any attempt to understanding city-regional processes and practices. There is a real danger that a search for rationality and an attempt to identify and theorize city-regions or regeneration economies leads to conceptual distortions. This explains why no adequate theory of city-region competitiveness or economic performance exists or perhaps will ever exist.

The social sciences have been trying to develop theory that can be applied to understand city-regions, but these theories tend to be stylized (Clark, 1998) or indicative with no predictive ability. They act as floodlights to illuminate aspects of city-regions, but have limited or no explanatory power. Social science has also tried to develop rigorous and systematic methods and techniques as analytical approaches to exploring city-region problems and challenges. There are many problems here, but there are four that are critical. First, there is the continual problem with data. There are whole areas of city-region activity in which there is no data and other areas in which only proxy measures exist. Firm-level data is always problematic as the quality of the data reflects the ability of a representative of a firm to provide an adequate account of some aspect of the firm's activities. The analysis of financial accounts is complicated by the adoption of particular accounting approaches, assumptions and conventions by each firm. Second, the data that exists often only provides a trace of the outcome of a set of complex and simple decisions that include trade-offs, negotiations, information asymmetry and irrationality. Third, the research adopts a narrow and often disciplinary constrained perspective. Fourth, the danger of assuming that patterns and order can be identified in social and economic activities that are the outcome of decisions based on bounded rationality.

A good example of this problem is found in a study that attempted to understand the locational decision-making processes of 59 companies (Townroe, 1972). This analysis involved collecting 64 variables as separate measures of firm characteristics and locational search behaviour. These variables were then analysed to search for behavioural regularities. This analysis failed to identify any distinct patterns or regularities, but instead confirmed that the locational decision-making processes of these firms were heterogeneous, reflecting a diversity of experiences. There is 
a real danger that the analysis of city-region socio-economic activity is based on the analysis of averages of many different types of behaviour. The result is often an analysis based on representative firms or individuals, but the difficulty is that there is no such thing as both firms and individuals are heterogeneous and often idiosyncratic.

It is always dangerous to assume that the decisions that underpin the geographic organization of production are in any way rational. All investment decisions that involve fixing capital in land and buildings result in sunk costs and contribute to path dependency (Bryson et al., 2017b). It is important not to assume that the organization of a production process is the outcome of a logical or rational decision-making process. The relationship between path dependency and investment decisions implies that a decision to invest in one location, at one point in time, might have reflected the outcome of a rational decision-making process based on all available information. Nevertheless, circumstances will have altered and the investment decision may no longer appear rational in terms of any risk versus reward or return calculation. Florence identifies three situations in which irrationality distorts the geographic organization of production (Florence, 1953: 89-90):

1. Firms make investment decisions irrationally without any calculation of risk versus reward. Such decisions may reflect path dependency in which incremental decisions are made to continue to invest in a site without any attempt to consider alternative locations. This is an example of an ongoing accumulation of investment decisions that are based on obsolete logic.

2. A firm makes an informed investment decision but ignores or discounts the longer-term costs of what might eventually become an unsuitable location.

3. A firm makes an investment decision informed by an appropriate calculation of risk versus reward, but the outcome of this decision is undermined or distorted and no longer meets present-day circumstances.

A city-region or regeneration economy is the product of isolated incremental decision-making. Some of these decisions are made locally, some made in the very distant past and some by individuals or firms located elsewhere. Some of these decisions will be completely irrational while others reflect attempts to make informed decisions. The resilience and performance of a city-region economy is thus the outcome of millions upon millions of decisions that are layered on top of one another, resulting in a complex concatenation of co-located economic and social activities. The outcome might be a balanced, resilient and diversified local economy. A city-region that has become a regeneration economy with high levels of unemployment is often the outcome of over-reliance on a few economic sectors that have been undermined by process and technological innovations.

Drawing upon this, it is important to keep in mind that the majority of firms have a relatively short history. The history of a city-region economy is one of a process which involves the formation, restructuring and failure of firms. This includes mergers and acquisitions (M\&A) but also processes by which a firm established 
in one place is eventually captured by a firm located in another place as firms try to grow through acquisition. This process of firm capture may involve closure and the transfer of a production process and/or brand to another location. Surviving firms will go through a continual process of adaptation and evolution (Bryson and Ronayne, 2014). Old firms are unusual. In a study of old firms in the Netherlands, Brouwer (2005) identified 362 firms that met the following definition:

A firm stays the same firm if the product stays the same or is differentiated in the same product-line, and the name of the company has been unaltered. Age is defined in years since the founding, old are those firms that were founded before 1851 and still exist today. (Brouwer, 2005: 34, italics in original)

There is a problem with this definition as alterations in management and ownership are excluded as it is considered that such changes do not affect a firm's identity. The conclusion to this study notes that research has tended to ignore older firms and the ways in which "regional circumstances may perhaps have favoured them" (Brouwer, 2005: 220).

\section{A systemic or integrated approach to researching city-regions as regeneration economies}

Researching city-region regeneration economies is a difficult task. There are many ways of researching city-regions. These include Scott's (2002) concept of 'global city' region as a special subset of very distinctive and super-connected places or Robinson's (2005) ordinary cities. There are many similar definitions of city-regions including liveable cities, connected cities, authentic cities, knowledge or learning regions, creative city-regions and smart cities. These include a particular focus on one element of the complex system of systems that comprises a city-region. Thus, the object of study, or unit of analysis, of a city-region economy research project might focus on:

- From region to firm.

- From region to an industry or industrial sector.

- From industry to firm.

- From firm to individual (managers, employees).

- From firm to cluster or city-region.

- Entrepreneurship and small and medium-sized enterprises.

- International business.

- Foreign direct investment and international business.

- Global value chains/global production networks.

- Evolution.

- Energy flows and systems.

- Climate change including mitigation and adaptation.

- Regional resilience.

- Spatial planning. 
- Buildings - housing, offices, shops, factories, warehouses, schools, hospitals.

- Commercial property development and investment.

- Finance - financialization.

- Social policy.

- Innovation ecosystems.

- Flows - ideas, people, finance/investment.

- Connections and connectivity.

- Traded and untraded interdependencies.

- Assets - physical infrastructure (road, rail, air, water, digital, sub-surface infrastructure - pipes and cables, etc.), buildings, educational assets.

- Green infrastructure including biodiversity.

- Local and national infrastructure.

- People - diversity, skills, linkages to other places.

- History - cultural and heritage assets.

- Governance.

- Connections (includes foreign direct investment, migrants, etc.).

Each reflects a conceptual, empirical or even disciplinary focus on understanding city-regions. Each provides a partial rather than a holistic analysis. It is very difficult, perhaps impossible, to develop a holistic, integrated or systematic analysis of a city-region economy. The scale of this task makes this difficult in terms of resources, time, capabilities and institutional structures that favour disciplinary rather than multi-disciplinary research. It is further complicated by difficulties over access to both qualitative and quantitative datasets. This book aims to move beyond partial understandings of city-region regeneration economies to try to develop more holistic or integrated forms of understanding.

\section{Conclusion and structure of the book}

This edited collection is a call for research on city-regions to develop a holistic and multi-disciplinary or trans-disciplinary approach. It aims to illuminate some of the 'problems' facing such city-regions and to highlight and address research questions around the complexity and multi-dimensional nature of city-regions (time, multiscalar, multi-disciplinary) and regeneration economies with their blend of internal and external drivers. The book is structured into ten chapters.

The second chapter, written by Geoffrey Hewings, explores trade in goods, services and people and the role this plays in regenerating economies. The argument is based on the belief that there is a real need to combine both macro and micro perspectives. This approach explores the networks of interactions between diverse agencies within regions and the necessity of placing a regional economy in a broader context by considering external linkages. The discussion in this chapter has highlighted two main challenges facing regional economies - trade in goods and services and trade in people. These challenges have become ever-more complex but what academia can do is contribute to enhanced understanding of how an economy works, how it 
is changing, how future demands for its goods and services will evolve, the needs in terms of investment in human capital, in housing, in infrastructure and in the capacity to adapt to change.

In the third chapter, Robert Stimson, draws upon his research on Australian cityregions to explore better ways to measure regional economic performance and to identify those factors which might explain spatial differentiation in regional performance with a focus on endogenous factors. A key strand that is interlaced through this chapter is an appreciation of the importance of context and place. In other words, geography does matter. Another dimension is an appreciation of the performance, dynamics and measurement of very diverse city-regions.

A very different approach is developed in the fourth chapter by Andrew Weaver. This adopts a thematic approach with a focus on skills. In this analysis the focus is on exploring initially conventional economic frameworks for conceptualizing the relationships between skills and growth, followed by an assessment of empirical findings about skills and growth and the measurement of skills. The chapter then emphasizes the importance of the relationships between skills, context and local institutions focusing on occupational approaches, historical/network frameworks, and skill system analysis. The conclusion identifies a future research agenda for understanding skills and economic development in the context of city-regions.

Chapter 5 provides a very different framing for understanding city-regions. This chapter, by Godfrey Yeung, explores global production networks (GPN) as a firmcentric and geographically-attuned heuristic framework for examining how firm and non-firm actors influence the products and services produced and distributed across space. It highlights the spatial asymmetrical capture of value-added in different manufacturing activities controlled by various transnational corporations and their sub-contractors, hence, the subsequent spatial inequality in regional development. In spite of its usefulness in explaining inequality in regional development, there are blind spots in the GPN framework, from manufacturing and economic-centric aspects (not paying enough attention to the importance of services and logistics, or the social and environmental aspect of upgrading) to an over-reliance on micro-scale case studies. The recent introduction of GPN 2.0 arguably provides better guidance for researchers on how the GPN framework operates and assists with charting the possible trajectories of value capture, enhancement and retention in regeneration economies.

In Chapter 6, Nicholas Kreston and Dariusz Wójcik explore the resilience of US metropolitan areas and the 2008 financial crisis. This analysis seeks to explain why only a minority of US metropolitan areas recovered rapidly following the 2008 banking crisis and recession of 2007-2009. An uneven pattern of growth came into being over the course of the recession and persisted through 2013 and this was evident in both total employment and on a sectoral basis. Using cluster analysis, the best performing group of metropolitan areas as exhibiting less economic sectorial diversity than average and lower rates of subprime mortgages as a share of all households is identified. The worst performing areas show the highest average rates 
of household distress as well as bank failures. The chapter concludes by recommending further research into the conditions of financial distress amongst metropolitan areas as well as into the nature of sector specialization, as both potential factors affecting growth.

The relationship between governance, policy and regional development is explored by Jennifer Clark in Chapter 7. This chapter discusses the processes and actors implicated in regeneration economies and their respective, observed roles in contributing to regional growth and decline. It draws upon examples primarily from the US, to highlight how empirical research on regional growth and change is indeed contributing to a research agenda that is informing policy development that is capable of supporting economic regeneration. A key question that is considered is: "what then can regional studies say about what we know about what works (and what does not) in building a set of policies that promote regeneration economies supported at the national scale and implemented at the regional scale?" It is noted that ultimately the answer to this question is both retrospective in cataloguing what can be gleaned from the preponderance of existing evidence and prospective in setting the agenda for future research. This chapter highlights key aspects of that future research agenda.

In Chapter 8, Emmanouil Tranos, John Steenbruggen and Peter Nijkamp explore mobile phone operators, big data and urban analysis. This chapter adopts a methodological approach for exploring the existing state-of-the-art of urban analysis based on big data obtained from mobile phone operators. Urban analysts have begun to explore the application of 'new' sources of big data to understanding cities. Perhaps these big data sources need to be relabelled as another form of microdata as they chart the everyday and often second-by-second interactions between people, place and space. The analysis of big data is beginning to reveal the dynamics of cities and diurnal patterns. Nevertheless, this understanding of people and place is yet to be incorporated into mainstream urban analysis and into models intended to predict the growth patterns of cities and regions. This chapter highlights the opportunities for developing a big data informed view of city-regions.

The relationship between research, public policy and local economies is explored by Max Nathan in Chapter 9. The analysis is based on a discussion of how researchpolicy interactions and challenges play out by exploring a recently established government experiment in the UK - the 'What Works' network. This has established a number of 'What Works Centres' that gather, evaluate and translate evidence on policy effectiveness across nine broad policy areas. The aim is to assist public sector decision makers in developing effective policy interventions. In this chapter, Nathan explores the role of evidence in policymaking identifying several constraints in the effective use of research in policy development and implementation. The chapter then reviews the key findings of the What Works Centre for Local Economic Growth and discusses the implications for local policy-makers. The chapter concludes with broader reflections on the political economy of evidence and the linkages between researchers and policy-makers. 
In the concluding chapter, the editors explore the relationships between people, place, space and city-regions by considering the development of an integrated or systemic approach for researching city-regions as regeneration economies. This chapter is intended to identify questions rather than to provide solutions. A critical issue to consider is the importance of place or context. Thus, city-regions are heterogeneous, complex and extremely diverse. On the one hand, every city-region is distinct or unique and is the reflection of place-based incremental decision-making that has produced a distinct set of localized structures, assets, resources, investments, firms, linkages, relationships, people, history and identity. On the other hand, all city-regions have within them a complex and ever-evolving mosaic of different types of place. Thus, there is as much diversity within as there is between different city-regions.

This book aims to open new ways of thinking about city-regions as regeneration economies and regional economics and to directly, and in the best possible ways, impact on the everyday lives of city-region residents. This is a call not for policyrelevant research, but rather for research that directly and indirectly transforms everyday lives producing better outcomes for people. This is not about measurable impacts, but rather about invisible but extremely significant impacts. It is these types of unmeasurable and unknowable transformational impacts that should be one of the drivers behind all research undertaken on city-region regeneration economies.

\section{References}

Bacharach, S.B. (1989), 'Organizational Theories: Some Criteria for Evaluation', Academy of Management Review, 14(4): 496-515.

Bell, D. and Jayne, M. (2009), 'Small Cities? Towards a Research Agenda', International Journal of Urban and Regional Research, 33(3): 683-699.

Bluestone, B. and Harrison, B. (1982), The Deindustrialisation of America, Basic Books: New York.

Boschma, R. and Martin, R. (eds) (2010), The Handbook of Evolutionary Economic Geography, Edward Elgar Publishing: Cheltenham, UK and Northampton, MA, USA.

Brouwer, A.E. (2005), Old Firms in the Netherlands: The Long-term Spatial Impacts of Firms' Identities and Embeddedness, Netherlands Geographic Studies 329: Groningen.

Bryson J.R. (2018), 'Worker to Robot or Self-employment and the Gig Economy? Divisions of Labour, Technology and the Transformation of Work', in Paasi, A., Harrison, J. and Jones, M. (eds), Handbook on the Geographies of Regions and Territories, Edward Elgar Publishing: Cheltenham, UK and Northampton, MA, USA, in press.

Bryson, J.R. and Ronayne, M. (2014), 'Manufacturing Carpets and Technical Textiles: Routines, Resources, Capabilities, Adaptation, Innovation and the Evolution of the British Textile Industry', Cambridge Journal of Regions, Society and Economy, 7: 471-488.

Bryson, J.R., Clark, J. and Mulhall, R.A. (2017a), 'Beyond the Post-Industrial City? The Third Industrial Revolution, Digital Manufacturing and the Transformation of Homes in to Miniature Factories' in Nawratek, K. (ed.), Urban Re-industrialization, Punctum, New York: 107-116.

Bryson, J.R., Mulhall, R.A., Song, M. and Kenny, R. (2017b), 'Urban Assets and the Financialisation Fix: Land Tenure, Renewal and Path Dependency in the City of Birmingham', Cambridge Journal of Regions, Economy and Society, 1-15. 
Bryson, J.R., Mulhall, R.A., Song, M., Loo, B.P.Y, Dawson, R.J. and Rogers, C.D.F. (2018), 'AlternativeSubstitute Business Models and the Provision of Local Infrastructure: Alterity as a Solution to Financialization and Public-Sector Failure', Geoforum, in press.

Clancey, G. (2004), 'Local Memory and Worldly Narrative: The Remote City in America and Japan', Urban Studies, 41(12): 2335-2355.

Clark, G.L. (1998), 'Stylized Facts and Close Dialogue: Methodology in Economic Geography', Annals of the Association of American Geographers, 88(1): 73-87.

Coe, N.M. and Yeung, H.WC. (2015), Global Production Networks: Theorizing Economic Development in an Interconnected World, Oxford: Oxford University Press.

Coe, N.M., Hess, M., Yeung, H.W., Dicken, P. and Henderson, J. (2004), “Globalising” Regional Development: A Global Production Networks Perspective', Transactions of the Institute of British Geographers, NS29: 4: 468-484.

Crilley, L.R., Bloss, W.J., Yin, J., Beddows, D.C.S., Harrison, R.M., Allan, J.D., Young, D.E., Flynn, M., Williams, P., Zotter, P., Prevot, A.S.H., Heal, M.R., Barlow, J.F., Halios, C.H., Lee, J.D., Szidat, S. and Mohr, C. (2015), 'Sources and Contributions of Wood Smoke During Winter in London: Assessing Local and Regional Influences', Atmospheric Chemistry and Physics, 15: 3149-3317.

Dresser, M. and Fleming, P. (2009), Bristol: Ethnic Minorities and the City: 1000-2001, Phillimore: Chichester.

Exley, K., Robertson, S., Pope, F.D., Harrison, R.M. and Gant, T.W. (2014), 'Sources, Quantification and Health Implications Of Bioaerosols', American Journal of Pharmacology and Toxicology, 9(3): 189-199.

Florence, P.S. (1953), The Logic of British and American Industry: A Realistic Analysis of Economic Structure and Governance, Routledge and Kegan Paul: London.

Garnsey, E. and Cannon-Brookes, A. (1993), 'The "Cambridge Phenomenon" Revisited: Aggregate Change Among Cambridge High-Technology Companies Since 1985', Entrepreneurship \& Regional Development, 5: 179-207.

Garnsey E. and Heffernan P. (2005), 'High-Technology Clustering Through Spin-Out and Attraction: The Cambridge Case', Regional Studies, 39: 1127-1144.

Gereffi, G., Humphrey, J. and Sturgeon, T. (2005), 'The Governance of Global Value Chains', Review of International Political Economy, 12(1): 78-104.

Gibson-Graham, J.K. (1996), The End of Capitalism (As We Knew It): A Feminist Critique of Political Economy, Blackwell: London.

Hale, J.D., Pugh, T.A.M., Sadler, J.P., Boyko, C.T., Brown, J., Caputo, S., Caserio, M., Coles, R., Farmani, R., Hales, C., Horsey, R., Hunt, D.V.L., Leach, J.M., Rogers, C.D.F. and MacKenzie, R.A. (2015), 'Delivering a Multi-Functional and Resilient Urban Forest', Sustainability, 7: 4600-4624.

Hamilton, H. (1926), The English Brass \& Copper Industries, Longmans, Green and Co: London.

Harris, C., Jackson, L., Piekut, A. and Valentine, G. (2016), 'Attitudes Towards the "Stranger": Negotiating Encounters with Difference in the UK and Poland', Social \& Cultural Geography, 18(1): 16-33.

Harris, C., Moran, D. and Bryson, J.R. (2012), 'EU Accession Migration: National Insurance Number Allocations and the Geographies of Polish Labour Immigration to the UK', Tijdschrift voor economische en sociale geografie, 103(2): 209-221.

Harris, C., Moran, D. and Bryson, J.R. (2014), 'Polish Labour Migration to the UK: Data Discrepancies, Migrant Distributions and Indicators of Entrepreneurial Activity', Growth and Change, 46(2): 196-217.

Harrison, R.M. and Beddows, D.C. (2017), 'Efficacy of Recent Emissions Controls on Road Vehicles in Europe and Implications for Public Health', Scientific Reports, 7 (1152).

Harvey, D. (2014), Seventeen Contradictions and the End of Capitalism, Profile Books: London. Hunt, D.V.L., Lombardi, D.R., Atkinson, S., Barber, A.R.G., Barnes, M., Boyko, C.T., Brown, J., Bryson, J.R., Butler, D., Caputo, S., Caserio, M., Coles, R., Cooper, R.F.D., Farmani, R., Gaterell, M.R., Hale, J.D., Hales, C., Hewitt, C.N., Jankovic, L., Jefferson, I., Leach, J.M., MacKenzie, A.R., Memon, F., Pugh, 
T.A.M., Rogers, C.D.F., Sadler, J.P., Weingaertner, C. and Whyatt, J.D. (2012), Using Scenarios to Explore Urban UK Futures: A Review of Futures Literature from 1997 to 2011, BRE Press: Bracknell.

Isard, W. (1956), 'Regional Science, the Concept of Region, and Regional Structure', Papers and Proceedings of the Regional Science Association, 2: 13-26.

Keeble, D. (1969), 'Local Industrial Linkage and Manufacturing Growth', Town Planning Review, 40(2): $163-188$.

Keeble, D. (1989), 'High-Technology Industries and Regional Development in Britain: The Case of the Cambridge Phenomenon', Environment and Planning C. Government and Policy, 7: 153-172.

Kenney, M. and Zysman, J. (2016), 'The Rise of the Platform Economy', Issues in Science and Technology, 32: 61-69.

Leach, J.M., Lee, S.E., Hunt, D.V.L. and Rogers, C.D.F. (2017), 'Improving City-Scale Measures of Livable Sustainability: A Study of Urban Measurement and Assessment Through Application to the City of Birmingham, UK', Cities, 71 , in press.

Lloyd, G.I.H. (1913), The Cutlery Trade: An Historical Essay in the Economics of Small-Scale Production, Longmans, Green \& Co: London.

Martin, R. (2010), 'Roepke Lecture in Economic Geography: Rethinking Regional Path Dependence: Beyond Lock-In Evolution', Economic Geography, 86: 1-27.

Martin, R. (2012), '(Re)placing Path Dependence: A Response to the Debate', International Journal of Urban and Regional Research, 3: 179-192.

Massey, D. (1984), Spatial Divisions of Labour: Social Structure and the Geography of Production, Macmillan: London.

Massey, D. (1999), 'On Space and the City', in Massey, D., Allen, J. and Pile, S. (eds), City Worlds, Routledge: London: 115-171

Massey, D., Quintas, P. and Wield, D. (1992), High Tech Fantasies: Science Parks in Society, Science and Space, Routledge: London.

Mayer, H. and Knox, P. (2010), 'Small-Town Sustainability: Prospects in the Second Modernity', European Planning Studies, 18(10): 1545-1565.

Mayer, H., Habersetzer, A. and Meili, R. (2016), 'Rural-Urban Linkages and Sustainable Regional Development: The Role of Entrepreneurs in Linking Peripheries and Centers', Sustainability, 8(8), 745.

Nordigården, D., Rehme, J., Brege, S., Chicksand, D. and Walker, H. (2014), 'Outsourcing Decisions The Case of Parallel Production', International Journal of Operations \& Production Management, 34(8): 974-1002.

Parkinson, M., Meegan, R. and Karecha, J. (2015), 'City Size and Economic Performance: Is Bigger Better, Small More Beautiful Or Middling Marvellous?', European Planning Studies, 23(6): 1054-1068.

Petty, W. ([1678], 2004), Essays on Mankind and Political Arithmetic, Kessinger Publishing: Whitefish, MT. Ponte, S. and Sturgeon, T. (2014), 'Explaining Governance in Global Value Chains: A Modular TheoryBuilding Effort', Review of International Political Economy, 21(1): 195-223.

Reuver, M., Sorensen, C. and Basole, R. (2017), 'The Digital Platform: A Research Agenda', Journal of Information Technology, 1: 1-12.

Robinson, J. (2005), Ordinary Cities, Routledge: London.

Rogers, C.D.F., Bouch, C.J., Williams, S., Barber, A.R.G., Baker, C.J., Bryson, J.R., Chapman, D.N., Chapman, L., Coaffee, J., Jefferson, I. and Quinn, A.D. (2012), 'Resistance and Resilience - Paradigms for Critical Local Infrastructure', Proceedings of the Institution of Civil Engineers, Municipal Engineer, 165(2): 73-84.

Samoli, E., Atkinson, R.W., Analitis, A., Fuller, G.W., Beddows, D., Green, D.C., Mudway, I.S., Harrison, R.M., Anderson, H.R. and Kelly, F.J. (2016), 'Health Effects of Short-Term Exposure to SourceSpecific Particles in London, U.K.', Environment International, 97: 246-253.

Scott, A. (2002), 'Introduction', Global City-Regions: Trends, Theory, Policy, Oxford University Press:

Oxford: $11-33$. 
Smith A. ([1776], 1977), The Wealth of Nations, Penguin: Harmondsworth.

Sunley, P. (2008), 'Relational Economic Geography: A Partial Understanding or a New Paradigm?', Economic Geography, 84(1): 1-26.

Taylor, M. (2010), 'Clusters: A Mesmerising Mantra', Tijdschrift voor economische en sociale geografie, 101: $276-286$.

Tobler, W. (1970), 'A Computer Simulating Urban Growth in the Detroit Region', Economic Geography, 46: $234-240$.

Torrance, M. (2009), 'Reconceptualizing Urban Governance through a New Paradigm for Urban Infrastructure Networks', Journal of Economic Geography, 9: 805-822.

Townroe, P.M. (1972), 'Some Behavioural Considerations in the Industrial Location Decision', Regional Studies, 6(3): 261-272.

Vanchan, V., Mulhall, R. and Bryson, J.R. (2018), 'Repatriation or Reshoring of Manufacturing to the US and UK: Dynamics and Global Production Networks or from Here to There and Back Again', Growth and Change, 49(1): 97-121.

Walters, P. (2013), The Story of Coventry, The History Press: Stroud.

Woodward, D. (2017), 'Searching for Isard's Regional Essence', The Review of Regional Studies, 47: $121-135$.

Yeung, H. and Coe, N. (2015), 'Toward a Dynamic Theory of Global Production Networks', Economic Geography, 9(1): 29-58. 